\title{
Mutant p53-R273H mediates cancer cell survival and anoikis resistance through AKT-dependent suppression of BCL2-modifying factor (BMF)
}

\author{
BS Tan ${ }^{1,2}$, KH Tiong ${ }^{1,3,4}$, HL Choo ${ }^{1,2}$, F Fei-Lei Chung ${ }^{2}$, L-W Hii ${ }^{1,2}$, SH Tan ${ }^{1,2}$, IKS Yap ${ }^{5}$, S Pani ${ }^{6}$, NTW Khor ${ }^{7}$, SF Wong ${ }^{8}$, R Rosli ${ }^{9}$, \\ S-K Cheong ${ }^{10}$ and C-O Leong ${ }^{*, 1,2,5}$
}

p53 is the most frequently mutated tumor-suppressor gene in human cancers. Unlike other tumor-suppressor genes, p53 mutations mainly occur as missense mutations within the DNA-binding domain, leading to the expression of full-length mutant p53 protein. Mutant p53 proteins not only lose their tumor-suppressor function, but may also gain new oncogenic functions and promote tumorigenesis. Here, we showed that silencing of endogenous p53-R273H contact mutant, but not p53-R175H conformational mutant, reduced AKT phosphorylation, induced BCL2-modifying factor (BMF) expression, sensitized BIM dissociation from BCL- $X_{\mathrm{L}}$ and induced mitochondria-dependent apoptosis in cancer cells. Importantly, cancer cells harboring endogenous p53-R273H mutant were also found to be inherently resistant to anoikis and lack BMF induction following culture in suspension. Underlying these activities is the ability of $\mathrm{p53}-\mathrm{R} 273 \mathrm{H}$ mutant to suppress BMF expression that is dependent on constitutively active PI3K/AKT signaling. Collectively, these findings suggest that p53-R273H can specifically drive AKT signaling and suppress BMF expression, resulting in enhanced cell survivability and anoikis resistance. These findings open the possibility that blocking of PI3K/AKT will have therapeutic benefit in mutant p53-R273H expressing cancers.

Cell Death and Disease (2015) 6, e1826; doi:10.1038/cddis.2015.191; published online 16 July 2015

The p53 protein is a tumor suppressor that functions as a sequence-specific transcription factor regulating the expression of various target genes involved in apoptosis, cell-cycle arrest, DNA repair, senescence, and inhibition of angiogenesis and metastasis. ${ }^{1}$ However, approximately $50 \%$ of all human cancers contain a mutation in the TP53 gene, with the majority of these mutations occurring within the DNA-binding domain, causing an impaired binding of p53 to the DNA. ${ }^{2-5}$ Unlike most tumor-suppressor genes, which are predominantly inactivated by deletions or truncating mutations during cancer progression, the TP53 gene in human tumors is often found to undergo missense mutations that produce a fulllength protein containing only a single amino acid substitution with a greatly prolonged half-life. ${ }^{6,7}$

Most of the cancer-associated TP53 mutations can be ascribed to two main classes: DNA contact and conformational mutants. The first group includes mutations in residues directly involved in DNA binding (e.g., R248Q and R273H).
The second group comprises mutations that cause local (e.g., R249S and G245S) or global conformational distortions (e.g., R175H and R282W) ${ }^{8-10}$ The biological consequences of p53 mutations range from the mere loss-of-function to gainof-function. Many in vitro studies have clearly demonstrated that some p53 mutants can acquire new functions, thereby contributing actively to the tumor initiation, progression and the increased resistance to conventional anticancer treatments. ${ }^{3,10-13}$ Indeed, mice knocked in with mutant $\mathrm{p} 53-\mathrm{R} 270 \mathrm{H}$ or $\mathrm{p} 53-\mathrm{R} 172 \mathrm{H}$, corresponding to the human hotspot p53-R273H and p53-R175H mutants, respectively, developed highly metastatic tumors compared with p53-null mice, supporting the notion of gain-of-function properties acquired by mutant p53. ${ }^{14-19}$

At the molecular level, several mechanisms have been suggested to account for mutant p53 gain-of-function including transcriptional activation of MYC, BAG1, MDR1, NFKB2, EGR1, GEF-H1, ID4 and MAD1;20-29 transcriptional

\footnotetext{
${ }^{1}$ School of Postgraduate Studies, International Medical University, Bukit Jalil, Kuala Lumpur, Malaysia; ${ }^{2}$ Center for Cancer and Stem Cell Research, International Medical University, Bukit Jalil, Kuala Lumpur, Malaysia; ${ }^{3}$ Oral Cancer Research and Co-ordinating Center (OCRCC), Faculty of Dentistry, University of Malaya, Kuala Lumpur, Malaysia; ${ }^{4}$ Cancer Research Initiatives Foundation, Sime Darby Medical Centre, Subang Jaya, Malaysia; ${ }^{5}$ School of Pharmacy, International Medical University, Bukit Jalil, Kuala Lumpur, Malaysia; ${ }^{6}$ ANU Medical School, Canberra Hospital Campus, The Canberra Hospital Building 4, Garran, Australia; ${ }^{7}$ School of Medicine, Faculty of Medical and Health Sciences, The University of Auckland, Auckland, New Zealand; ${ }^{8}$ School of Medicine, International Medical University, Bukit Jalil, Kuala Lumpur, Malaysia; ${ }^{9}$ UPMMAKNA Cancer Research Laboratory, Institute of Bioscience, Universiti Putra Malaysia, 43400 UPM Serdang, Selangor, Malaysia and ${ }^{10} \mathrm{Faculty}$ of Medicine and Health Sciences, University Tunku Abdul Rahman, Bandar Sungai Long, Selangor, Malaysia

${ }^{*}$ Corresponding author: C-O Leong, Center for Cancer and Stem Cell Research, International Medical University, 126 Jalan 19/155B, Bukit Jalil, Kuala Lumpur, 57000, Malaysia. Tel: +603 2731 7528; Fax: +603 8656 7229; E-mail: cheeonn_leong@imu.edu.my

Abbreviations: 7-AAD, 7-aminoactinomycin D; AKT, v-akt murine thymoma viral oncogene homolog 1; ATF3, activating transcription factor 3; B2M, beta-2-microglobulin; BAD, BCL2-associated agonist of cell death; BAG1, BCL2-associated athanogene; BAX, BCL2-associated X protein; BCL-2, B-cell CLL/lymphoma 2; BCL-X $\mathrm{L}_{\mathrm{L}}, \mathrm{BCL2}$-like 1 (BCL2L1); BID, BH3 interacting domain death agonist; BIM, BCL2-like 11 (apoptosis facilitator) (BCL2L11); BMF, Bcl2-modifying factor; BOK, BCL2-related ovarian killer; BRD1, bromodomain containing 1; CD-95, Fas cell surface death receptor (also known as FAS); DEPDC1, DEP domain containing 1; Dicer, dicer 1, ribonuclease type III; DTT, Dithiothreitol; EGF, epidermal growth factor; EGFR, epidermal growth factor receptor; EGR1, early growth response 1; GAPDH, glyceraldehyde-3-phosphate dehydrogenase; GEF-H1, Rho/Rac guanine nucleotide exchange factor (GEF) 2 (also known as ARHGEF2)

Received 15.4.15; revised 25.5.15; accepted 09.6.15; Edited by G Raschellà
} 
repression of ATF3, CD-95, ID2, hTERT and MST1; ${ }^{30-33}$ unique interaction with specific DNA motives such as the nuclear matrix/scaffold attachment regions; ${ }^{34}$ epigenetic modification, ${ }^{35}$ regulation of miRNA ${ }^{36-38}$ and interactions with other proteins (e.g., p63, p73, NFY and BRD1). ${ }^{39-42}$

Previous studies from our laboratories have demonstrated that a subset of tumor-derived p53 mutants mediate cell survival in breast cancer cells that expressed them. ${ }^{43} \mathrm{We}$ found that silencing of mutant p53-R273H in MDA-MB-468 cells induced massive apoptosis. ${ }^{43}$ Importantly, the apoptotic effects following mutant p53 knockdown were independent of TAp63 and TAp73 function. Although considerable evidence is available documenting potential mechanisms through which p53 mutants deregulate cell growth, the mechanisms through which mutant p53 proteins enhance tumor cell survival remain relatively unexplored.

In the present study, therefore, we have investigated the effects of gain-of-function p53 mutants on deregulation of cell survival. We found that the p53-R273 contact mutant, but not the p53-R175 conformational mutant, promotes cancer cell survival and resistance to anoikis of cancer cells. Underlying these activities is the ability of $\mathrm{p} 53-\mathrm{R} 273 \mathrm{H}$ mutant to suppress BMF expression in a way that is dependent on PI3K/AKT signaling pathway. Our results, thus, provided yet another mechanism as to how the mutant p53 proteins can contribute to diverse oncogenic and pro-metastatic signaling.

\section{Results}

Knockdown of endogenous p53-R273H contact mutant, but not $\mathrm{R} 175 \mathrm{H}$ conformational mutant, induces mitochondria-dependent apoptosis. To determine the functional roles of p53 mutants in human breast cancer cells, endogenous p53 gene was silenced using lentiviral shRNA transduction. As shown in Figures $1 \mathrm{a}$ and $\mathrm{c}$ and Supplementary Figure 1, the silencing of endogenous p53$\mathrm{R} 273 \mathrm{H}$ contact mutant p53 by two independent p53-specific lentiviral shRNAs in MDA-MB-468 (breast), HT29 (colon) and A431 (epidermoid) cells induced massive apoptotic cell death as evidenced by PARP cleavage, cell blebbing and annexin V/7-AAD staining. In addition, caspase 3, caspase 9 and, to a lesser extent, caspase 8 activities were significantly upregulated following mutant $\mathrm{p} 53-\mathrm{R} 273 \mathrm{H}$ knockdown in MDA-MB-468 cells (Figure 1d). Inhibition of caspase 9, caspase 3 and pan-caspase activities blocked the apoptosis induced by silencing of p53-R273H, whereas inhibition of caspase 8 activity did not rescue the cells from undergoing apoptosis, suggesting that the induction of apoptosis following p53-R273H depletion required caspase 9 and caspase 3, but not caspase 8 activity (Figure 1e). Consistently, depletion of endogenous p53-R273H in MDA-MB-468 cells also induced a significant amount of mitochondrial depolarization (Figure 1f). In contrast, no apoptotic effects were observed in MCF-7 cells that express wild-type p53, nor in SKBR3 cells that express p53-R175H conformational mutant (Figure 1a and Supplementary Figure 1c). These results suggest that endogenous p53-R273H contact mutant is mediating the survival of breast cancer cells by suppressing the mitochondrial apoptotic pathway.
Depletion of mutant p53-R273H induces BCL2-modifying factor (BMF). Because BCL2 family proteins have been shown to have a critical role in mitochondria-dependent apoptotic pathway, we hypothesize that mutant p53-R273H might mediate the survival of breast cancer cells through regulation of $\mathrm{BCL}-2$ family proteins expression. To test this hypothesis, we investigated the expression of both pro- and anti-apoptotic BCL2 family proteins for their role in mitochondria-dependent apoptotic pathway. As shown in Figure 2a and Supplementary Figure 1a, one of the proapoptotic BCL2 family proteins, BMF, was upregulated at $48 \mathrm{~h}$ following depletion of endogenous $\mathrm{p} 53-\mathrm{R} 273 \mathrm{H}$, preceding the apoptotic event which occurred at $72 \mathrm{~h}$ (as indicated by PARP cleavage). In contrast, no significant difference in the expression of other pro-apoptotic (e.g., p-BAD, BAD, BAX, BID, BIM, PUMA and BOK) or anti-apoptotic (e.g., BCL-X and MCL-1) BCL-2 family members were observed (Supplementary Figure 2).

To further investigate whether upregulation of BMF occurred at the transcriptional level, real-time RT-PCR was performed to determine the level of BMF mRNA expression in MDA-MB-468 cells after p53-R273H knockdown. As shown in Figure 2b, knockdown of p53-R273H significantly induced BMF mRNA expression at 48 and $72 \mathrm{~h}$, corroborated with the upregulation of the protein levels. In contrast, no such induction was observed in the p53-R175H-expressing SKBR3 cells (data not shown). Notably, the suppression of BMF expression by mutant p53-R273H in breast cancer cells is independent of direct promoter binding, as no endogenous p53-R273H was detected at the BMF promoter by chromatin immunoprecipitation assay (Supplementary Figure 3).

BMF is required for the induction of apoptosis following depletion of endogenous p53-R273H. In order to test whether upregulation of BMF alone could induce apoptosis, ectopic expression of BMF was performed in MDA-MB-468 cells by transient transfection. As shown in Figure 2c, ectopic expression of BMF induces significant amount of apoptosis, suggesting that, indeed, overexpression of BMF could induce apoptosis in MDA-MB-468 cells.

We further investigated whether apoptosis induced by depletion of $\mathrm{p} 53-\mathrm{R} 273 \mathrm{H}$ required endogenous BMF function. Our result showed that depletion of $\mathrm{p} 53-\mathrm{R} 273 \mathrm{H}$ induced significant BMF upregulation in the vector control cells corroborated with significant apoptotic cell death (Figures 2d and e and Supplementary Figure 4); the levels of apoptosis were significantly reduced in BMF-depleted cells, suggesting that induction of apoptosis following p53-R273H depletion required BMF function.

Induction of BMF sensitizes the release of BIM from $B C L-X_{L}$ to promote mitochondrial apoptosis. Various studies showed that certain damage signals, such as loss of cell attachment, will release BMF, allowing it to translocate, and bind to the pro-apoptotic BH3-only proteins, BIM, displacing pro-survival BCL2 or $B C L-X_{L}$, to induce apoptosis. ${ }^{44-46}$ Here, we investigated whether the upregulation of BMF following depletion of endogenous p53-R273H in MDA-MB-468 cells might induce BCL- $\mathrm{X}_{\mathrm{L}} / \mathrm{BMF}$ heterodimerization and disrupt $B C L-X_{L} / B I M$ interaction. Indeed, our 


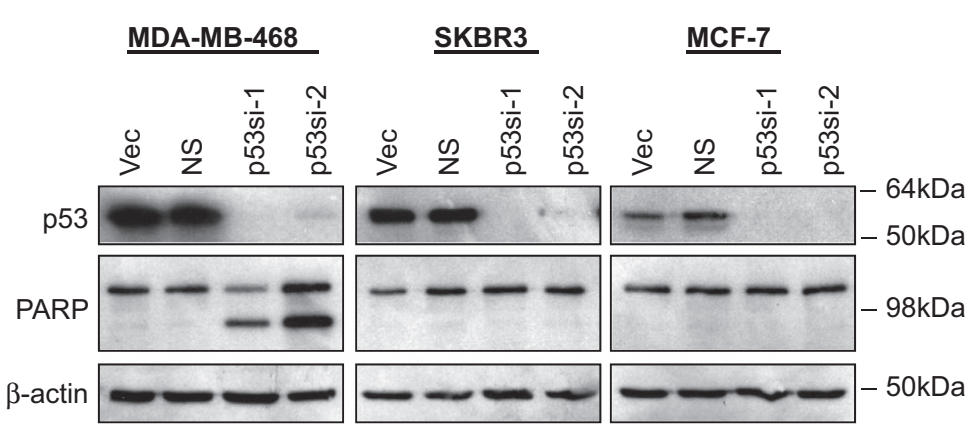

b MDA-MB-468

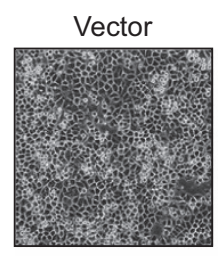

p53si-1
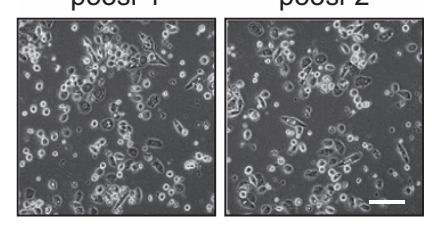

Scale bar $20 \mu \mathrm{m}$
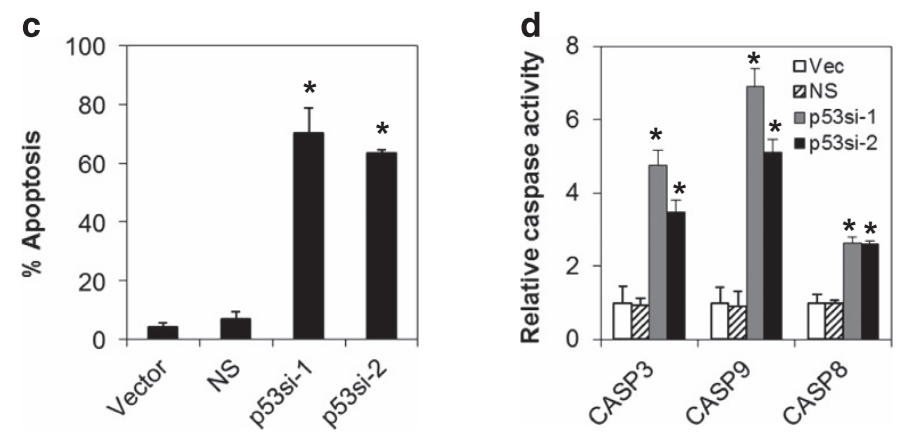

$\mathbf{f}$
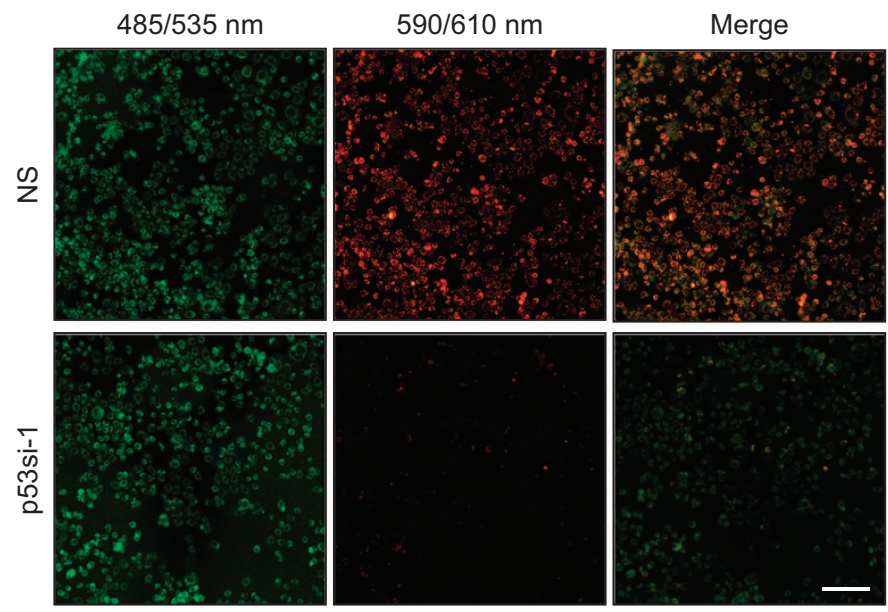

e

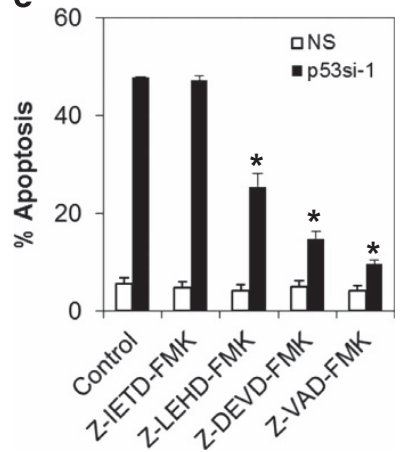

Figure 1 Knockdown of endogenous p53-R273H contact mutant, but not R175H conformational mutant, induces mitochondria-dependent apoptosis. (a-c) Mutant p53R273H is required for the survival of human breast cancer cells. Cells were transduced with control vector (vec), non-targeting (NS) and two different lentiviral constructs that specifically target human p53 (p53si-1 and p53si-2). Lysates were prepared for immunoblotting at $72 \mathrm{~h}$ after transduction. $\beta$-actin serves as a loading control. Morphological changes were observed at $96 \mathrm{~h}$ after lentiviral transduction by light microscopy (original magnification $\times 100$ ). Apoptotic cell death was determined using annexin V/7-AAD flow cytometry at $96 \mathrm{~h}$ after transduction. (d) Knockdown of mutant p53 induces caspase 8, 9 and 3 activation. Caspase activities were assessed by CaspaseGlo assay at $72 \mathrm{~h}$ following transduction. (e) Depletion of mutant p53 in MDA-MB-468 cells induces apoptosis which requires caspase 9 and 3, but not caspase 8, activities. Caspase-dependent cell death was evaluated by annexin V/7-AAD flow cytometry in the presence or absence of $20 \mu \mathrm{M}$ of caspase inhibitor following mutant p53-R273H knockdown. (f) Knockdown of mutant p53 in MDA-MB-468 cells induces mitochondrial membrane depolarization. Cells were stained with JC-1 at $72 \mathrm{~h}$ after p53 lentiviral shRNA transduction. Red color indicates the presence of JC-1 aggregates in intact mitochondria. Green color indicates JC-1 monomers in the cytoplasm. JC-1 stained cells were analyzed using epifluorescence microscopy (original magnification $\times 100$ ). Bars represent mean \pm S.D. of three experiments. * indicates statistical significance $(P<0.05)$ by Student's $t$-test

results demonstrated that $B C L-X_{L}$ bound to BIM but not BMF under normal conditions (Figure 3a). However, upon induction of BMF following p53-R273H knockdown, a significant amount of BMF was found to bind BCL- $X_{L}$, coinciding with the dissociation of BIM from BCL- $X_{L}$ (Figure 3a). Consistently, overexpression of $B C L-X_{L}$ completely abrogated the apoptotic effects of $\mathrm{p} 53-\mathrm{R} 273 \mathrm{H}$ depletion (Figures $3 b$ and $c$ ). Of note, no BCL-2 was detected in MDA-MB-468 cells. Together, 
a

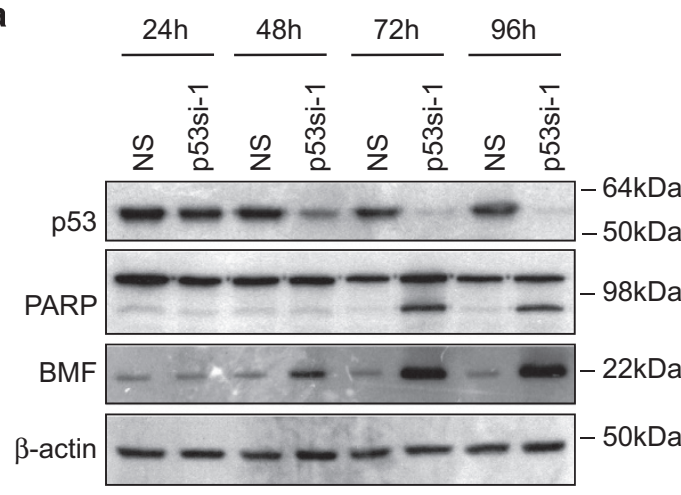

b

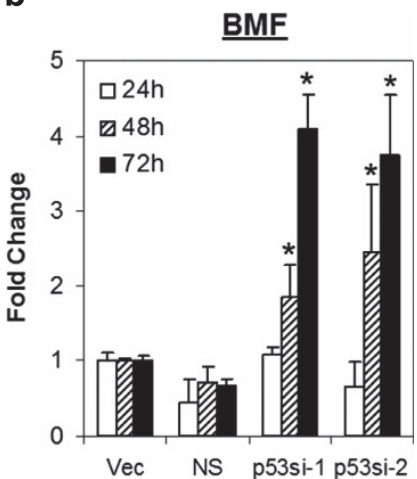

C

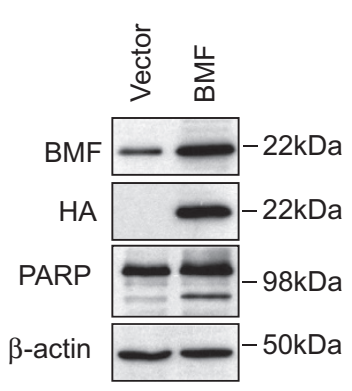

Vector

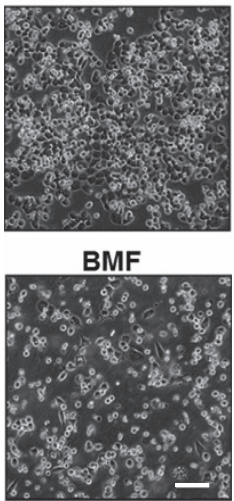

Scale bar $20 \mu \mathrm{m}$

d

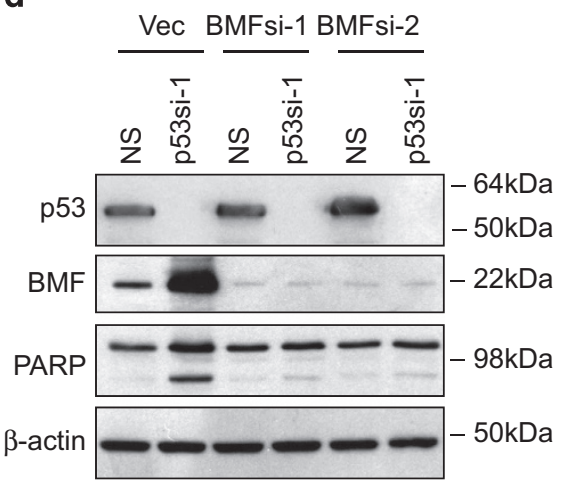

e

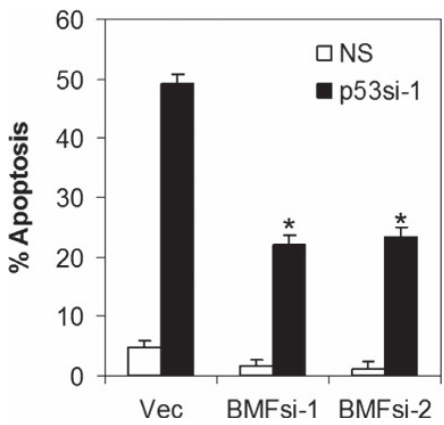

Figure 2 Depletion of mutant p53-R273H induces BMF. Knockdown of mutant p53 induces (a) BMF protein and (b) mRNA expression. MDA-MB-468 cells were transduced with p53 lentiviral shRNA. Protein and mRNA expression were accessed by immunoblot and quantitative RT-PCR, respectively. BMF mRNA expression was normalized against human GAPDH. (c) Ectopic expression of BMF is sufficient to induce apoptosis in MDA-MB-468 cells. Cells were transfected with $5 \mu \mathrm{g}$ of HA-tagged BMF using X-tremeGENE HP DNA transfection reagent as discussed in the Materials and Methods section. (d-e) Depletion of BMF rescues MDA-MB-468 cells from apoptosis induced by mutant p53 knockdown. Protein lysates and apoptosis were analyzed by (d) immunoblotting and (e) annexin V/7-AAD flow cytometry at $72 \mathrm{~h}$ after transduction. Bars represent mean \pm S.D. of three experiments. * indicates statistical significance $(P<0.05)$ by Student's $t$-test

these results suggest that silencing of endogenous mutant p53-R273H in MDA-MB-468 cells induced BMF expression and the formation of BMF/BCL- $X_{L}$ complexes. This in turn leads to the displacement of BIM from BCL- $X_{L}$ to induce apoptosis.

Mutant p53-R273H suppresses cellular anoikis. Because our results showed that endogenous p53-R273H mediates the survival of breast cancer cells through suppression of BMF and that BMF has been reported to mediate cellular anoikis, ${ }^{44,47}$ we hypothesized that $\mathrm{p} 53-\mathrm{R} 273 \mathrm{H}$ could also exert its oncogenic function through the suppression of cellular anoikis in cancer cells. To test this hypothesis, we examined the sensitivity of a number of cancer cell lines harboring different p53 mutations to anoikis. As shown in Table 1, more than 50\% apoptotic cell death was observed in cancer cell lines expressing wild-type p53 or various mutants (R280T, R175H, R179R, L194F and M246I) in suspension culture. In contrast, cancer cells expressing p53-R273H (MDA-MB-468, HT29 and A431) exhibit significant resistance to anoikis. Similarly, significant BMF mRNA and protein induction was also observed in the anoikis-sensitive MCF-7 and MCF-10A (wild-type p53), and SKBR3 (p53-R175H) cells, whereas no significant BMF induction was observed in 


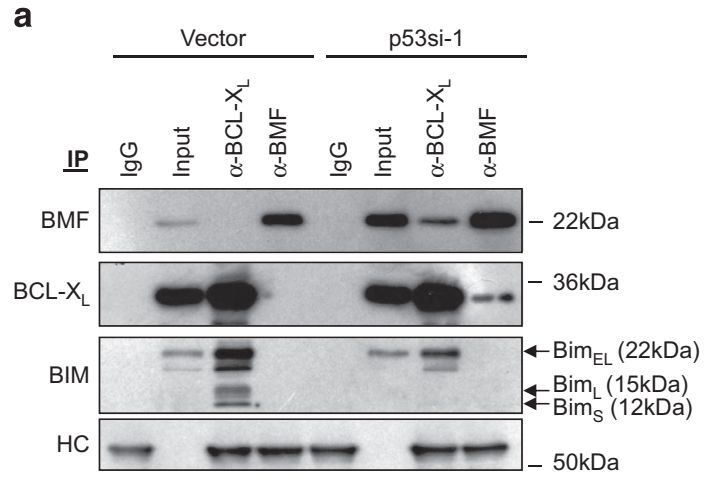

b
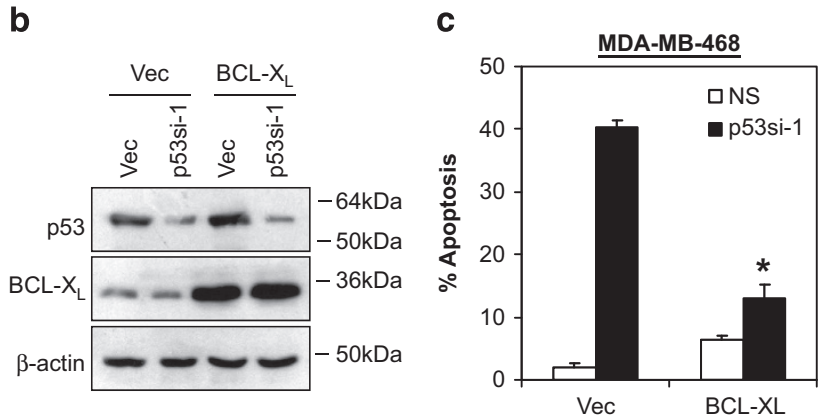

Figure 3 Induction of BMF sensitizes the release of BIM from BCL-X $X_{L}$. (a) MDAMB-468 cells were transduced with non-targeting shRNA (NS) or p53si-1 lentiviral shRNA for $72 \mathrm{~h}$ and the interaction of BMF/BCL- $\mathrm{X}_{\mathrm{L}}$ and BIM/BCL- $\mathrm{X}_{\mathrm{L}}$ was detected by co-immunoprecipitation assay. Inputs for co-immunoprecipitation were also subjected to immunoblot analysis. Ig $\mathrm{G}$ and heavy chain $(\mathrm{HC})$ were used as a negative control and loading control, respectively. (b-c) Overexpression of BCL- $X_{L}$ abrogated the apoptotic effects of mutant p53-R273H knockdown in MDA-MB-468 cells. Cells were co-transfected with BCL- $X_{L}$ expression construct and p53si-1 shRNA. Protein lysates and apoptosis were analyzed by immunoblotting and annexin V/7-AAD flow cytometry at $72 \mathrm{~h}$ after co-transfection. Bars represent mean \pm S.D. of three experiments. *indicates statistical significance $(P<0.05)$ by Student's $t$-test as compared with vector control cells

Table 1 Cancer cells harboring mutant p53-R273H are inherently resistant to anoikis in suspension cell culture

\begin{tabular}{lllll}
\hline \multirow{2}{*}{ Tumor type } & Cell line & \multirow{2}{*}{ p53 status } & \multicolumn{2}{c}{ Apoptotic cells, \% \pm S.D. } \\
\cline { 3 - 5 } & & & Attached & Suspension \\
\hline Breast & MDA-MB-468 & R273H & $0.12 \pm 0.05$ & $14.43 \pm 2.43$ \\
Colon & HT29 & R273H & $0.49 \pm 0.23$ & $13.28 \pm 2.56$ \\
Epidermoid & A431 & R273H & $0.56 \pm 0.23$ & $37.05 \pm 2.89$ \\
Breast & HCC38 & R273L & $1.55 \pm 0.40$ & $59.70 \pm 0.92$ \\
Breast & SKBR3 & R175H & $1.65 \pm 0.12$ & $52.24 \pm 2.94$ \\
Colon & KM12 & H179R & $0.72 \pm 0.08$ & $64.75 \pm 3.78$ \\
Nasopharynx & CNE1 & R280H & $0.79 \pm 0.21$ & $75.87 \pm 3.58$ \\
Breast & T47D & L194F & $0.11 \pm 0.04$ & $88.82 \pm 0.25$ \\
Lung & H23 & M246I & $0.91 \pm 0.13$ & $80.98 \pm 1.62$ \\
Breast & MCF-7 & WT & $1.80 \pm 1.02$ & $67.70 \pm 2.18$ \\
Breast & MCF-10A & WT & $0.68 \pm 0.43$ & $72.28 \pm 0.87$ \\
& & & & \\
\hline
\end{tabular}

the anoikis-resistant MDA-MB-468, HT29 and A431 cells which harbor p53-R273H mutation (Figures $4 \mathrm{a}$ and $\mathrm{c}$ and Supplementary Figure $5 \mathrm{a}$ and $\mathrm{b}$ ). These results suggest that p53-R273H mutant might inhibit cellular anoikis through suppression of BMF induction.
To directly validate whether the $\mathrm{p} 53-\mathrm{R} 273 \mathrm{H}$ contact mutant was indeed capable of suppressing BMF expression and anoikis, and not because of the inherent anoikis resistance of the MDA-MB-468, HT29 or A431 cells, we performed a gene reconstitution experiment in the non-transformed MCF-10A cells. A pool of MCF-10A cells stably transduced with a lentiviral p53 shRNA targeting the endogenous $3^{\prime}$-UTR of the wild-type p53 (p53si-3) was generated followed by ectopic transient expression of the p53-R175H or p53-R273H mutants. The levels of anoikis were then analyzed by culturing the transfected cells on poly-HEMA-treated tissue culture plates followed by annexin V/7-AAD flow cytometry analysis.

As shown in Figure $4 d$, more than $80 \%$ of the endogenous p53 expression was downregulated in cells stably expressing p53si-3 shRNA in MCF-10A cells. As expected, detachment of cells induced significant upregulation of BMF mRNA and protein levels in the vector control cells and the p53-R175H expressing MCF-10A (Figure 4d and Supplementary Figure 5c). In contrast, no such upregulation of BMF was observed in cells transfected with $\mathrm{p} 53-\mathrm{R} 273 \mathrm{H}$ mutant, suggesting that p53-R273H, but not p53-R175H, suppresses BMF expression in MCF-10A cells growing in suspension. Consistently, p53-R273H-expressing MCF-10A cells were significantly more resistant to anoikis as compared with vector or p53-R175H-expressing cells $(P<0.05$, Student's $t$-test) (Figure 4e). Similar results were also observed in p53-null H1299 lung cancer cells (Supplementary Figures 5d and e), suggesting that the p53-R273H contact mutant, but not the p53-R175H conformational mutant, confers anoikis resistance in human cancer cells.

Mutant p53-R273H regulates PI3K/AKT signaling pathway. In order to identify the mechanism by which mutant p53-R273H mediates tumor cell survival and anoikis resistance, microarray gene profiling was conducted following endogenous p53-R273H depletion in MDA-MB-468 cells. $A$ total of 58 genes were upregulated ( $>1.5$ fold-change), while 117 genes were downregulated at $72 \mathrm{~h}$ following p53-R273H knockdown (Supplementary Figure 6). Of note, the microarray results show that BMF expression was upregulated while p53 mRNA was downregulated following knockdown of p53-R273H in MDA-MB-468 cells, independently validating our previous results which demonstrated that depletion of $\mathrm{p} 53-\mathrm{R} 273 \mathrm{H}$ induces BMF mRNA and protein expression.

To validate the microarray results, we performed independent real-time RT-PCR on a number of candidate genes. Indeed, the expression of LZTFL1, POU2F3 and SOSTDC1 was upregulated in a time-dependent manner following p53-R273H knockdown in MDA-MB-468 cells, while TMBIM1, ICAM1 and LIFR were significantly downregulated, consistent with the microarray data (Supplementary Figure 6).

Having ascertained the p53-R273H gene signature, we sought to identify the direct molecular target of p53-R273H using the Connectivity Map resource. ${ }^{48,49}$ The Connectivity Map consists of pattern-matching software that compares an input gene signature to a database of 7000 expression profiles representing 1309 small molecules (termed perturbagens). A connectivity score from +1 to -1 is then assigned based on the degree of similarity or dissimilarity between 
a

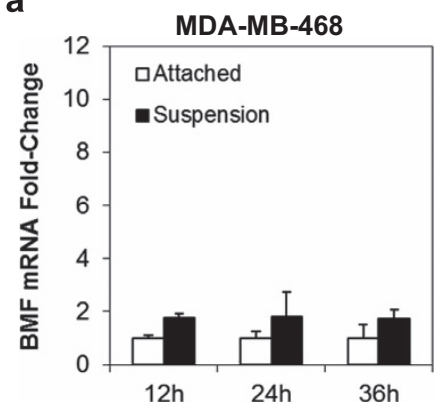

b

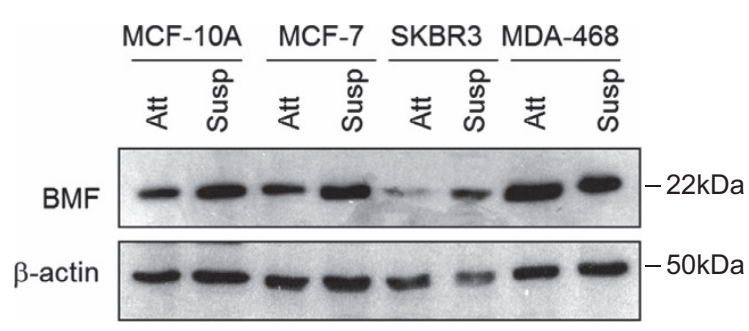

SKBR3

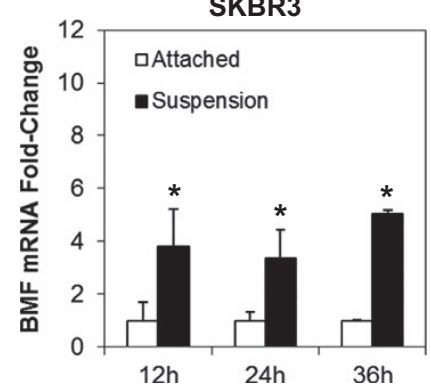

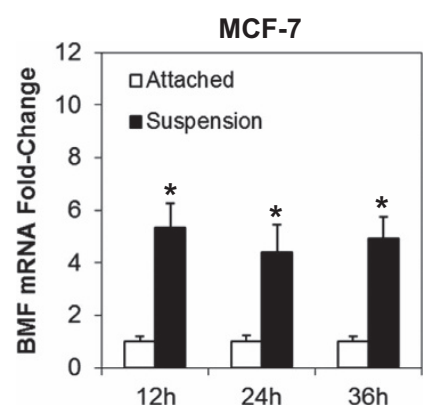

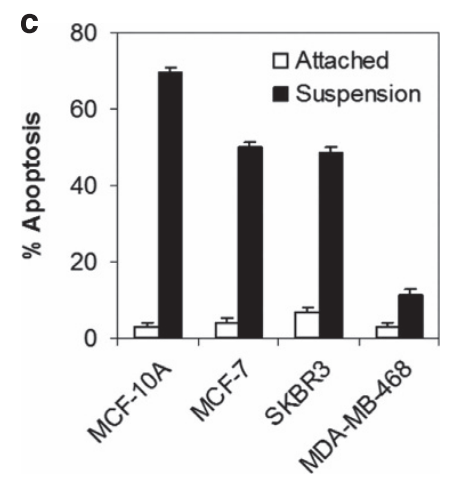

d

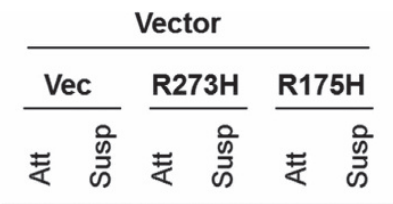

p53

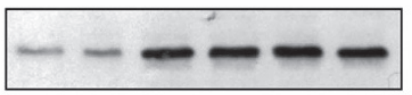

BMF

$\beta$-actin
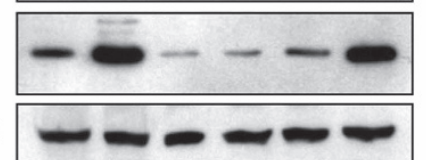

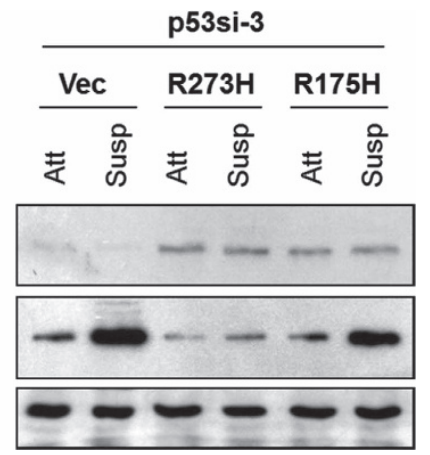

e

Figure 4 Mutant p53-R273H suppresses cellular anoikis. (a-b) Endogenous p53-R273H suppresses BMF induction in breast cancer cells cultured in suspension. Total RNA samples and protein lysates derived from cells cultured as attached monolayers or in suspension were subjected to real-time RT-PCR analysis and immunoblotting, respectively. (c) p53-R273H expressing MDA-MB-468 cells were inherently resistant to anoikis. All cells were cultured as in a. Apoptosis/anoikis was determined using annexin V/7-AAD flow cytometry. (d) Ectopic expression of p53-R273H, but not p53-R175H, suppresses BMF protein and mRNA induction (Supplementary Figure 5c) in MCF-10A cells cultured in suspension. MCF-10A p53si-3 cells were transfected with vector, p53-R175H- or p53-R273H-expressing plasmid. Protein lysates derived from cells cultured as attached monolayers (att) or in suspension (susp) were subjected to immunoblotting. (e) Ectopic expression of p53-R273H confers anoikis resistance in MCF-10A cells. MCF-10A p53si-3 cells were cultured and transfected as in $\mathrm{d}$. Apoptosis was analyzed by annexin V/7-AAD flow cytometry at $48 \mathrm{~h}$ after culture. Bar represents mean \pm S.D. of three independent experiments. * indicates statistical significancet $(P<0.05)$ by Student's $t$-test

the two signatures..$^{48,49}$ Thus, a drug with a high connectivity score and low $P$ value has a gene signature very similar to the query signature and might be hypothesized to act on a pathway in parallel with the drug that generated the query signature.

The Connectivity Map analysis shows that three of the top five perturbagens predicted to share common pathways activated by p53-R273H depletion in MDA-MB-468 cells were either direct or indirect inhibitors of PI3K signaling pathway (Table 2). These include wortmannin and LY-294002, which are PI3K inhibitors, ${ }^{50}$ and sirolimus, an mTOR inhibitor. ${ }^{51}$ In addition, we also identified vorinostat and trichostatin $\mathrm{A}$, both are histone deacetylase inhibitors, as one of the hits following p53-R273H knockdown. However, unlike the PI3K inhibitors, the gene signature that was enriched following p53-R273H knockdown was inversely correlated with the gene signatures induced by histone deacetylase inhibitors. These findings led us to hypothesize that p53-R273H might exert its gain-offunction effects through activation of PI3K/AKT signaling pathway and/or inhibition of histone deacetylase activities.

Depletion of p53-R273H dephosphorylates AKT. To directly test this hypothesis, immunoblotting was performed to evaluate the expression of phosphorylated AKT following p53-R273H knockdown in MDA-MB-468 cells.

As shown in Figure $5 \mathrm{a}$ and Supplementary Figure $7 \mathrm{a}$, induction of BMF following depletion of endogenous p53-R273H corroborated with the reduction of AKT 
Table 2 Top 25 pharmaceutical perturbagens identified through the Connectivity Map that induce a genes signature following p53-R273H depletion

\begin{tabular}{|c|c|c|c|c|}
\hline Rank & Pharmaceutical pertubagen & $P$-value & Mean connectivity score ${ }^{a}$ & Description \\
\hline 1 & Vorinostat & $<1.0 \mathrm{E}-05$ & -0.450 & Histone deacetylase inhibitors \\
\hline 2 & Wortmannin & $<1.0 \mathrm{E}-05$ & 0.261 & PI3Ks inhibitor \\
\hline 3 & Trichostatin A & $<1.0 \mathrm{E}-05$ & -0.413 & Histone deacetylase inhibitors \\
\hline 4 & Sirolimus & $<1.0 \mathrm{E}-05$ & 0.297 & mTOR inhibitor \\
\hline 5 & LY-294002 & $<1.0 \mathrm{E}-05$ & 0.352 & PI3Ks inhibitor \\
\hline 6 & Prestwick-664 & 1.1E-03 & 0.440 & - \\
\hline 7 & AG-013608 & 1.7E-03 & 0.423 & - \\
\hline 8 & Amikacin & 1.9E-03 & 0.559 & Aminoglycoside antibiotic \\
\hline 9 & Mometasone & 2.0E-03 & -0.471 & Glucocorticosteroid \\
\hline 10 & $\mathrm{H}-7$ & 2.1E-03 & -0.458 & - \\
\hline 11 & Phenoxybenzamine & 2.4E-03 & 0.510 & Alpha antagonist \\
\hline 12 & Liothyronine & 3.0E-03 & 0.553 & Thyroid hormone \\
\hline 13 & Betazole & $3.2 \mathrm{E}-03$ & -0.345 & Histamine $\mathrm{H} 2$ receptor agonist \\
\hline 14 & Demecarium bromide & 3.6E-03 & -0.412 & Acetylcholinesterase inhibitor \\
\hline 15 & Piroxicam & 4.3E-03 & 0.430 & NSAID \\
\hline 16 & Nalbuphine & 5.0E-03 & -0.277 & Analgesic \\
\hline 17 & 0179445-0000 & 5.1E-03 & 0.255 & - \\
\hline 18 & Mianserin & $6.2 \mathrm{E}-03$ & -0.426 & Tetracyclic antidepressant \\
\hline 19 & Naphazoline & 8.1E-03 & 0.389 & Vasoconstrictor \\
\hline 20 & Felodipine & 8.1E-03 & -0.249 & Calcium channel blocker \\
\hline 21 & Guaifenesin & 8.7E-03 & 0.449 & Expectorant drug \\
\hline 22 & Ikarugamycin & 1.0E-02 & -0.447 & Antibiotic \\
\hline 23 & Tomatidine & 1.1E-02 & 0.326 & Steroidal alkaloid \\
\hline 24 & Caffeic acid & $1.2 \mathrm{E}-02$ & 0.580 & - \\
\hline 25 & Deferoxamine & 1.2E-02 & 0.355 & Chelating agent \\
\hline
\end{tabular}

${ }^{a}$ Mean connectivity score among all treatment instances

phosphorylation at serine 473 and threonine 308. Similarly, ectopic expression of p53-R273H in MCF-10A p53si-3 or H1299 cells induced significant AKT phosphorylation and suppression of BMF, whereas no such effects were observed in cells transfected with $\mathrm{p} 53-\mathrm{R} 175 \mathrm{H}$, nor in cells transfected with vector control (Figure 5b and Supplementary Figure 7b ).

We further investigated the dependence of p53-R273Hmediated BMF suppression and cell survival on AKT activity. Indeed, the expression of a constitutively active myristoylated AKT completely abrogated the induction of BMF and dramatically reduced apoptosis following $\mathrm{p53}-\mathrm{R} 273 \mathrm{H}$ depletion in MDA-MB-468, HT29 and A431 cells (Figures $5 c$ and d and Supplementary Figures 7c and d). Together, these results demonstrate that $\mathrm{p} 53-\mathrm{R} 273 \mathrm{H}$ mutant is capable of regulating PI3K and AKT signaling.

Mutant p53-R273H regulates specifically AKT and BMF expression in a wide range of cancer cells. To determine whether the pro-survival effect of mutant $\mathrm{p} 53-\mathrm{R} 273 \mathrm{H}$ is present in other tumor types, we performed p53 gene knockdown in a panel of human cancer cell lines harboring various p53 mutations. As shown in Figure 6, depletion of endogenous p53-R273H in MDA-MB-468, HT29 and A431 induced significant amount of apoptosis and BMF expression, consistent with our previous observations.

Intriguingly, depletion of endogenous p53-R280K in MDA-MB-231 and p53-R280T in CNE-1 cells also reduced AKT phosphorylation, but instead of upregulation, BMF expression was found to be significantly downregulated and no apoptotic cell death was observed. In stark contrast, depletion of p53-M246I in $\mathrm{NCl}-\mathrm{H} 23$ lung cancer cells led to BMF downregulation with unchanged phospho-AKT levels. The levels of phosho-AKT and BMF remained unaffected in SKBR3 (p53-R175H), KM12 (p53-H179R),
MCF-7 (wild-type p53) or MCF-10A (wild-type p53) following endogenous p53 knockdown. These results suggest that mutant p53-R273H, but not other mutants, specifically regulate tumor cell survival through AKT-dependent suppression of AKT.

p53 mutant correlates with AKT phosphorylation in primary breast tumors. Because our results predict that tumors with mutant p53 would show more active PI3K/AKT signaling, we stained tissue microarrays of human breast cancer samples for p53 and compared this with the levels of AKT phosphorylation. We used high p53 staining as an indication of the presence of potential gain-of-function p53 mutations (Supplementary Figure 6). Consistent with our model, a significant positive correlation $(P<0.001$, Chi-square test) was detected between elevated p53 staining and high levels of AKT phosphorylation (Supplementary Figure 8). Collectively, these results suggest that p53 mutants specifically drive cancer cell survival and anoikis resistance through alteration of AKT signaling.

\section{Discussion}

This study describes a gain-of-function of mutant p53-R273H in promoting both cell survival and anoikis resistance of cancer cells. Underlying these activities is the ability of mutant $\mathrm{p} 53-\mathrm{R} 273 \mathrm{H}$ to suppress BMF expression in a way that is dependent on PI3K/AKT signaling pathway. Depletion of endogenous p53-R273H hot-spot contact mutant, but not the $\mathrm{p} 53-\mathrm{R} 175 \mathrm{H}$ conformational mutant, downregulated AKT phosphorylation, induced BMF expression, sensitized BIM dissociation from BCL- $X_{L}$ and induced significant mitochondria-dependent apoptosis in a wide range of cancer cells. Importantly, the knockdown of BMF or ectopic 
a

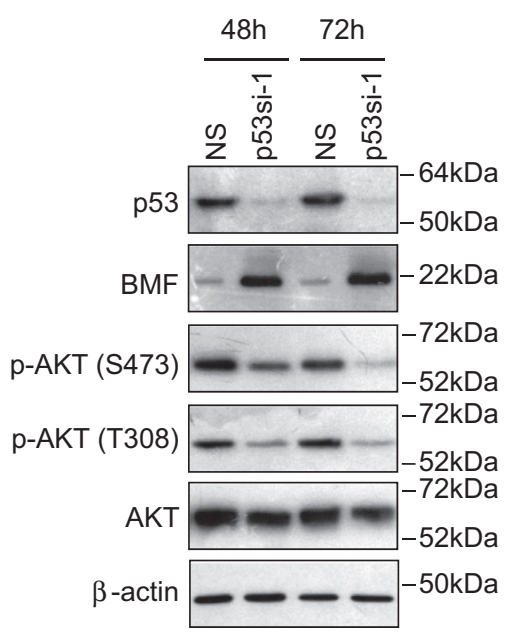

c

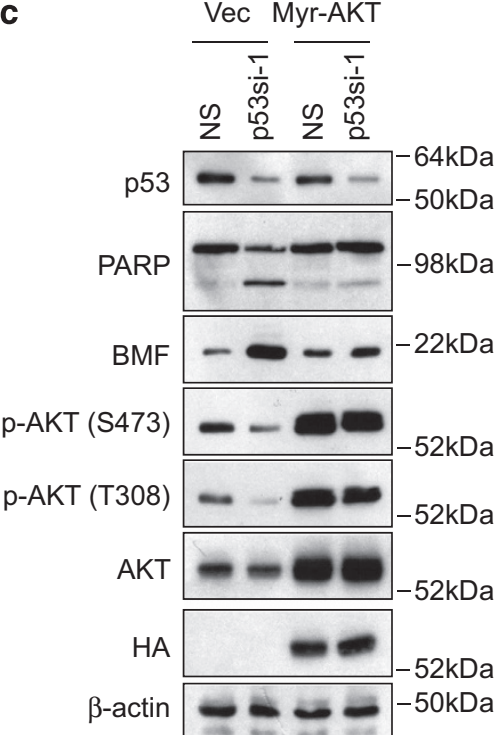

b

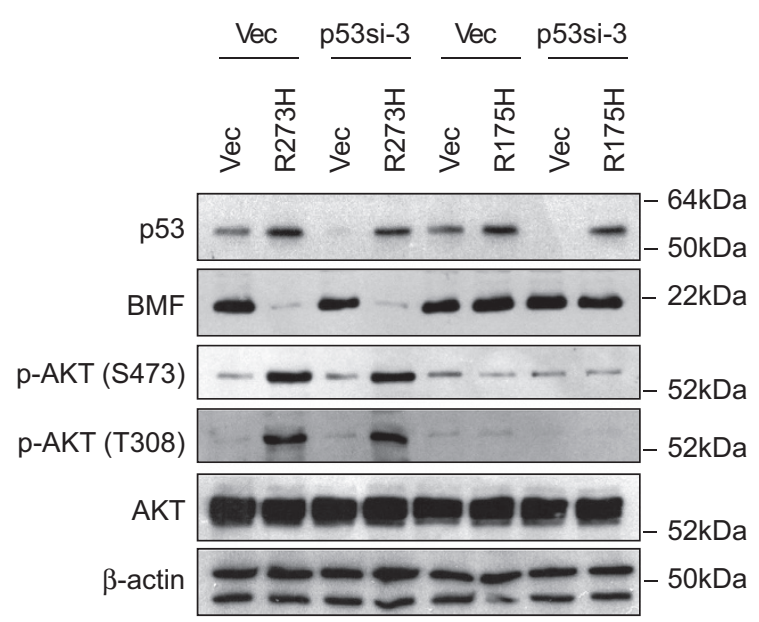

d

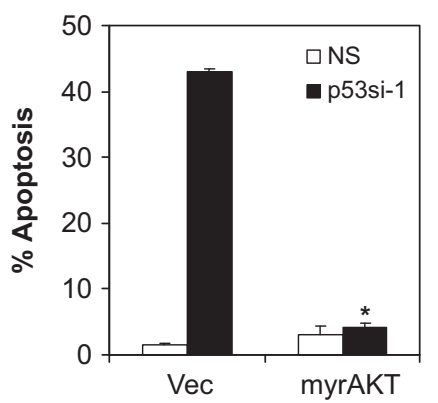

Figure 5 Mutant p53-R273H regulates PI3K/AKT signaling pathway. (a) Knockdown of p53-R273H in MDA-MB-468 cells reduces AKT phorphorylation. MDA-MB-468 cells were transduced with non-targeting (NS) or p53si-1 lentiviral shRNA and lysates were isolated for immunoblotting analysis at 48 and $72 \mathrm{~h}$ after transduction. (b) Ectopic expression of mutant p53-R273H, but not p53-R175H, induces AKT phosphorylation. MCF-10A cells were transduced with lentiviral vector or p53si-3 shRNAs targeting the $3^{\prime}$-UTR of the endogenous wild-type p53 followed by brief drug selection ( $1 \mu \mathrm{M}$ of puromycin). Pool of p53si-3 stably expressing cells 3 were transfected with vector, p53-R175H or p53-R273H followed by immunoblotting at $72 \mathrm{~h}$ after transfection. (c) Ectopic expression of myr-AKT suppresses BMF expression following p53-R273H knockdown in MDA-MB-468 cells. (d) Ectopic expression of myr-AKT abrogated the apoptotic effects induced by p53-R273H depletion in MDA-MB-468 cells. Cells were co-transfected with myr-AKT and p53si-1 for $72 \mathrm{~h}$. Apoptosis was determined using annexin V/7-AAD flow cytometry. Bar represents mean \pm S.D. of three independent experiments

expression of a myristoylated AKT significantly rescued the apoptotic effects of p53-R273H depletion, suggesting that BMF induction is required for the apoptotic cell death following p53-R273H knockdown. Similarly, cancer cells harboring endogenous $\mathrm{p} 53-\mathrm{R} 273 \mathrm{H}$ mutant were also found to be inherently resistant to anoikis and lack of BMF induction following culture in suspension. As predicted by this model, overexpression of $\mathrm{p} 53-\mathrm{R} 273 \mathrm{H}$, but not $\mathrm{p} 53-\mathrm{R} 175 \mathrm{H}$, in the $\mathrm{p} 53$ wild-type MCF-10A cells rendered the cells resistant to anoikis and suppresses BMF induction. These results suggest that mutant p53-R273H specifically drives cancer cell survival through suppression of BMF, which might contribute to increased anoikis resistance during metastasis. Because induction of BMF was also abolished in myristoylated
AKT-expressing cells following p53-R273H knockdown, it seems likely that the induction of BMF is downstream of AKT inhibition.

A further demonstration of the clinical relevance of the p53 mutants and PI3K/AKT axis was provided by IHC staining of primary human breast cancers showing a positive correlation between high expression of p53 (an indicator of the presence of gain-of-function mutant p53) and strong phospho-AKT staining.

It should be cautioned, though, that the effect of mutant p53 on PI3K/AKT signaling is not limited to only p53-R273H mutants. The results also do not necessarily imply that all tumors having high phospho-AKT levels would possess p53$\mathrm{R} 273 \mathrm{H}$ mutation and have the same degree of resistance to 

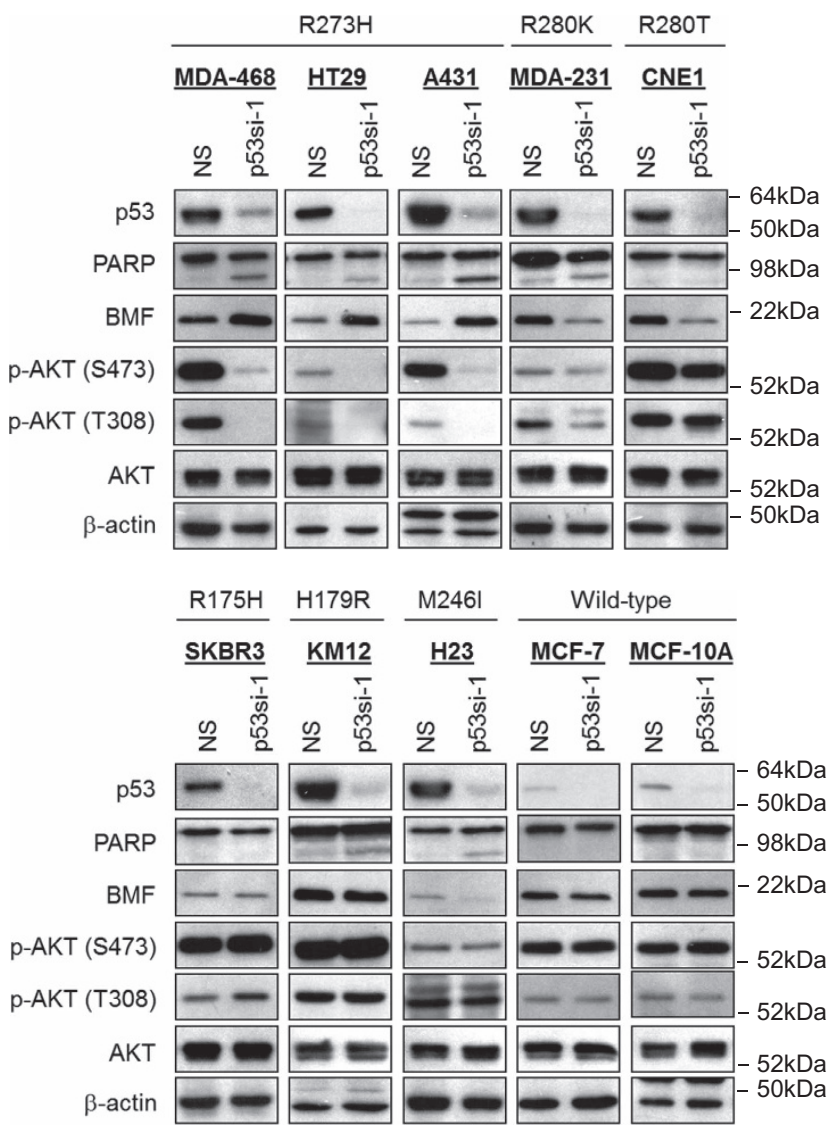

Figure 6 Mutant p53-R273H regulates AKT and BMF expression in a wide range of cancer cells. Cells were transduced with p53si-1 lentiviral shRNA. Protein lysates were isolated for immunoblotting at $72 \mathrm{~h}$ after transduction. Note the dephosphorylation of AKT corroborated with BMF induction only in cells bearing p53$\mathrm{R} 273 \mathrm{H}$.

apoptosis and anoikis. Indeed, depletion of endogenous p53R280K in MDA-MB-231 and p53-R280T in CNE-1 cells confers similar downregulation of phospho-AKT, but BMF expression was found to be significantly downregulated (instead of upregulated as observed in p53-R273Hexpressing cells) and no apoptotic cell death was observed. It seems likely that other p53 mutants might cooperate via different mechanisms, independent of BMF, to convey different oncogenic signals to promote aggressiveness in human cancers. This warrants further investigation.

How, exactly, p53 mutants contribute to PI3K/AKT activation remains an open question. Because p53 gain-of-function mutants can drive tumorigenesis through activation of growth factor receptors (e.g., TGF- $\beta$ receptor, ${ }^{52}$ EGFR $^{53-55}$ and $\mathrm{MET}^{56,57}$ ) or promote integrin/Rab-coupling protein-driven recycling. ${ }^{53}$ These signaling pathways have been implicated in the activation of PI3K/AKT signaling. Hence, it is tempting to speculate that the constitutive activation of PI3K/AKT by p53$\mathrm{R} 273 \mathrm{H}$ may be partly modulated by one or a combination of these mechanisms. Indeed, the three cell lines (MDA-MB-468, HT29 and A431) that were responsive to AKT de-phosphorylation, BMF induction and apoptotic cell death following p53-R273H depletion, express moderate to high levels of EGFR. ${ }^{58}$ Further work is indeed necessary to understand whether the role of mutant $p 53-\mathrm{R} 273 \mathrm{H}$ in the regulation of $\mathrm{PI} 3 \mathrm{~K} / \mathrm{AKT}$ signaling and BMF expression influences metastatic development in human cancers. Research addressing this aspect will also need to ascertain the relative contribution of each functional property of mutant p53-R273H, that is, control of apoptosis, cell migration and cell invasion, in tumorigenesis.

Finally, several studies have also revealed a role for TAp63, a p53 family protein and transcription factor, which interacts with mutant but not wild-type p53. ${ }^{59,60}$ By inhibiting TAp63, mutant p53 can regulate a pro-invasive transcription program that includes regulation of the expression of Dicer, DEPDC1, Cyclin G2 and Sharp1 ${ }^{52,61}$ However, our findings suggest that mutant $\mathrm{p} 53-\mathrm{R} 273 \mathrm{H}$ can regulate cancer cells survival and anoikis resistance independent of the TAp63 (and TAp73) functions. ${ }^{43}$ This is consistent with a previous study which shows that the loss of TAp63 is less potent in inducing metastasis as compared with mutant p53 expression in a mouse model of pancreatic ductal adenocarcinoma, suggesting that mutant p53 does more than inhibiting TAp63. ${ }^{62}$

In conclusion, we demonstrated that p53-R273H contact mutant suppresses BMF expression in a way that is dependent on PI3K/AKT signaling pathway to promote cancer cell survival and anoikis resistance. Our results, thus, provide evidence for another mechanism that tumors may use to promote metastasis, especially in tumors where mutant p53 is highly expressed. These findings also open the possibility that targeting PI3K/AKT signaling pathway will have therapeutic benefit in mutant $\mathrm{p} 53-\mathrm{R} 273 \mathrm{H}$ expressing cancers.

\section{Materials and Methods}

Cell culture and constructs. Human breast carcinoma cell lines (HCC38, MCF-7, MDA-MB-231, MDA-MB-468 and SKBR3), colon carcinoma cell lines ( $\mathrm{HT}-29$ and $\mathrm{KM} 12)$, lung carcinoma cell lines ( $\mathrm{NCl}-\mathrm{H} 1299$ and $\mathrm{NCl}-\mathrm{H} 23)$, epidermoid carcinoma (A431) and nasopharyngeal carcinoma (CNE1) cell lines were maintained in RPMl 1640 containing 10\% fetal bovine serum, $100 \mathrm{lU} / \mathrm{ml}$ penicillin, and $100 \mu \mathrm{g} / \mathrm{ml}$ streptomycin (Sigma-Aldrich, St Louis, MO, USA). MCF-10A cells were grown in DMEM-F12 (Sigma-Aldrich) supplemented with 5\% horse serum, $20 \mathrm{ng} / \mathrm{ml}$ EGF, $0.5 \mathrm{~g} / \mathrm{ml}$ hydrocortisone, $100 \mathrm{ng} / \mathrm{ml}$ cholera toxin, $10 \mu \mathrm{g} / \mathrm{ml}$ insulin, $100 \mathrm{IU} / \mathrm{ml}$ penicillin and $100 \mu \mathrm{g} / \mathrm{ml}$ streptomycin. All cells were maintained at $37^{\circ} \mathrm{C}$ in an environment containing $5 \% \mathrm{CO}_{2}$. Expression constructs were obtained from Addgene (Cambridge, MA, USA) and were transfected using X-tremeGENE HP DNA transfection reagent (Roche, Indianapolis, IN, USA) according to the manufacturer's instruction (Supplementary Table 1).

Lentiviral production and transduction. Lentiviral shRNA constructs were purchased from Sigma-Aldrich. High-titer lentiviral stocks were generated by co-transfection with packaging plasmids psPAX2 (Addgene; plasmid 12260) and envelope plasmids pMD2.G (Addgene; plasmid 12259) into HEK-293T cells as described previously. . $^{43,63-66}$ The shRNA target sequences for p53 and BMF are shown in Supplementary Table 2.

Immunoblot analysis. Protein lysates from cells were extracted in ice-cold lysis buffer $(0.75 \%$ NP- $40,1 \mathrm{mM}$ DTT, phosphatase inhibitors and protease inhibitors in PBS). Total protein $(50 \mu \mathrm{g})$ was subjected to SDS-PAGE followed by immunoblotting. Details of the source of antibodies used for immunoblotting are provided in the Supplementary Table 3.

Apoptosis and anoikis assay. Quantitation of apoptosis by Annexin V-PE/ 7-AAD staining was performed as described previously. ${ }^{43,63}$ All analysis was performed on a FACSCalibur flow cytometer using CellQuest Pro software (version 5.1.1; BD Biosciences, San Jose, CA, USA). For anoikis assay, cells were plated on tissue culture plates pretreated with $20 \mathrm{mg} / \mathrm{ml}$ of polyHEMA (Sigma, St. Louis, MO, USA) and analyzed for apoptosis by Annexin V-PE assay. 
Caspase activation and inhibition. Caspase 3, 8 and 9 activities in cells were measured at $72 \mathrm{~h}$ after lentiviral shRNAs transduction using a CaspaseGlo kit (Promega, Madison, WI, USA) according to the manufacturer's protocol. Caspase 3, 8,9 or pan-caspase inhibitor (Z-DEVD-FMK, Z-IETD-FMK, Z-LEHD-FMK and Z-VAD-FMK, respectively; Promega) was used to inhibit caspase activity. The optimum concentration of all inhibitors was determined to be $20 \mu \mathrm{M}$. Inhibitors were added to cells $24 \mathrm{~h}$ after lentiviral shRNA transduction. Apoptosis was measured by Annexin V-PE assay at $72 \mathrm{~h}$.

Mitochondrial membrane depolarization assay. Cells were incubated with $5 \mu \mathrm{g} / \mathrm{ml}$ of JC-1 (Merck, Darmstadt, Germany) in dark condition for $30 \mathrm{~min}$ at room temperature followed by visualization with fluorescence microscopy or flow cytometry analysis.

Quantitative RT-PCR. Total RNA from cells was extracted using Qiagen RNA isolation kit (Qiagen, Valencia, CA, USA) and first-strand CDNA was synthesized using High Capacity RNA-to-cDNA Master Mix (Applied Biosystems, Carlsbad, CA, USA) according to the manufacturers' protocol. Gene expression levels were measured by real-time RT-PCR using the FastStart Universal SYBR Green Master reagent (Roche) and a Bio-Rad iQ5 real-time PCR detector system (Bio-Rad, Richmond, CA, USA). Data analysis was performed using Bio-Rad iQ5 Optical System Software V1.0. The specific forward and reverse primer sequences are shown in Supplementary Table 4. The conditions for all real-time RT-PCR reactions were as follows: $3 \mathrm{~min}$ at $94^{\circ} \mathrm{C}$ followed by $40 \mathrm{~s}$ at $94^{\circ} \mathrm{C}, 40 \mathrm{~s}$ at $60^{\circ} \mathrm{C}$ and $25 \mathrm{~s}$ at $72^{\circ} \mathrm{C}$ for 40 cycles. The expression data were normalized against GAPDH or B2M as housekeeping gene.

Microarray and connectivity map analysis. Microarray experiments were performed in duplicate in MDA-MB-468 cells transduced with p53 lentiviral shRNA or with non-specific shRNA control for $48 \mathrm{~h}$. Isolated RNA was submitted to a Affymetrix certified service laboratory (Origen Labs, Singapore) for quality control and processing. All hybridization was performed on a Affymetrix Human Gene 1.OST Array. Microarray data analyses were performed using the Affymetrix Expression Console V1.1 (Santa Clara, CA, USA), Gene Set Enrichment Analysis (Broad Institute of Harvard and MIT, MA, USA) ${ }^{67}$ and the Connectivity Map. ${ }^{48}$ All microarray expression data have been deposited in the National Center for Biotechnology Information's Gene Expression Omnibus (GEO series accession number: GSE65967).

\section{Conflict of Interest}

The authors declare no conflict of interest.

Acknowledgements. We thank members of the IMU Institute for Research, Development and Innovation (IRDI) and IMU Cancer Research Center for helpful discussions. This work was supported by the Malaysian Ministry of Education Fundamental Research Grant Scheme (FRGS/2/2011/SKK/IMU/02/4). No sponsors of this work had any role in the design or conduct of the study; in the collection, analysis, and interpretation of the data; or in the preparation, review, or approval of the manuscript.

1. Lane DP. Cancer. p53, guardian of the genome. Nature 1992; 358: 15-16.

2. Olivier M, Hollstein M, Hainaut P. TP53 mutations in human cancers: origins, consequences, and clinical use. Cold Spring Harb Perspect Biol 2010; 2: a001008.

3. Sigal A, Rotter V. Oncogenic mutations of the p53 tumor suppressor: the demons of the guardian of the genome. Cancer Res 2000; 60: 6788-6793.

4. Hollstein M, Sidransky D, Vogelstein B, Harris CC. p53 mutations in human cancers. Science 1991; 253: 49-53.

5. Vogelstein B, Lane D, Levine AJ. Surfing the p53 network. Nature 2000; 408: 307-310.

6. Rivlin N, Brosh R, Oren M, Rotter V. Mutations in the p53 tumor suppressor gene: important milestones at the various steps of tumorigenesis. Genes Cancer 2011; 2: 466-474.

7. Petitjean A, Achatz MI, Borresen-Dale AL, Hainaut $P$, Olivier M. TP53 mutations in human cancers: functional selection and impact on cancer prognosis and outcomes. Oncogene 2007; 26: 2157-2165.

8. Muller PA, Vousden $\mathrm{KH}$. Mutant p53 in cancer: new functions and therapeutic opportunities. Cancer Cell 2014; 25: 304-317.

9. Solomon $\mathrm{H}$, Madar S, Rotter V. Mutant $\mathrm{p} 53$ gain of function is interwoven into the hallmarks of cancer. J Pathol 2011; 225: 475-478.
10. Goh AM, Coffill CR, Lane DP. The role of mutant p53 in human cancer. J Pathol 2011; 223 116-126.

11. Chee JL, Saidin S, Lane DP, Leong SM, Noll JE, Neilsen PM et al. Wild-type and mutant p53 mediate cisplatin resistance through interaction and inhibition of active caspase-9. Cell Cycle 2013; 12: 278-288.

12. Guo L, Liew HP, Camus S, Goh AM, Chee LL, Lunny DP et al. lonizing radiation induces a dramatic persistence of $p 53$ protein accumulation and DNA damage signaling in mutant p53 zebrafish. Oncogene 2013; 32: 4009-4016.

13. Fiorini C, Cordani M, Padroni C, Blandino G, Di Agostino S, Donadelli M. Mutant p53 stimulates chemoresistance of pancreatic adenocarcinoma cells to gemcitabine. Biochim Biophys Acta 2015; 1853: 89-100.

14. Lang GA, Iwakuma T, Suh YA, Liu G, Rao VA, Parant JM et al. Gain of function of a p53 hot spot mutation in a mouse model of Li-Fraumeni syndrome. Cell 2004; 119: 861-872.

15. Heinlein C, Krepulat F, Lohler J, Speidel D, Deppert W, Tolstonog GV. Mutant p53(R270H) gain of function phenotype in a mouse model for oncogene-induced mammary carcinogenesis. Int J Cancer 2008; 122: 1701-1709.

16. Olive KP, Tuveson DA, Ruhe ZC, Yin B, Willis NA, Bronson RT et al. Mutant p53 gain of function in two mouse models of Li-Fraumeni syndrome. Cell 2004; 119: 847-860.

17. Hanel W, Marchenko N, Xu S, Yu SX, Weng W, Moll U. Two hot spot mutant p53 mouse models display differential gain of function in tumorigenesis. Cell Death Differ 2013; 20: 898-909.

18. Doyle B, Morton JP, Delaney DW, Ridgway RA, Wilkins JA, Sansom OJ. p53 mutation and loss have different effects on tumourigenesis in a novel mouse model of pleomorphic rhabdomyosarcoma. J Pathol 2010; 222: 129-137.

19. Bossi G, Marampon F, Maor-Aloni R, Zani B, Rotter V, Oren M et al. Conditional RNA interference in vivo to study mutant p53 oncogenic gain of function on tumor malignancy. Cell Cycle 2008; 7: 1870-1879.

20. Solomon H, Buganim Y, Kogan-Sakin I, Pomeraniec L, Assia Y, Madar S et al. Various p53 mutant proteins differently regulate the Ras circuit to induce a cancer-related gene signature. J Cell Sci 2012; 125(Pt 13): 3144-3152.

21. Frazier MW, He X, Wang J, Gu Z, Cleveland JL, Zambetti GP. Activation of c-myc gene expression by tumor-derived p53 mutants requires a discrete $\mathrm{C}$-terminal domain. Mol Cell Biol 1998; 18: 3735-3743.

22. Yang X, Pater A, Tang SC. Cloning and characterization of the human BAG-1 gene promoter: upregulation by tumor-derived p53 mutants. Oncogene 1999; 18: 4546-4553.

23. Sampath J, Sun D, Kidd VJ, Grenet J, Gandhi A, Shapiro LH et al. Mutant p53 cooperates with ETS and selectively up-regulates human MDR1 not MRP1. J Biol Chem 2001; 276: 39359-39367.

24. Weisz L, Zalcenstein A, Stambolsky P, Cohen Y, Goldfinger N, Oren M et al. Transactivation of the EGR1 gene contributes to mutant p53 gain of function. Cancer Res 2004; 64: 8318-8327.

25. Mizuarai S, Yamanaka K, Kotani H. Mutant p53 induces the GEF-H1 oncogene, a guanine nucleotide exchange factor-H1 for RhoA, resulting in accelerated cell proliferation in tumor cells. Cancer Res 2006; 66: 6319-6326.

26. Scian MJ, Stagliano KE, Anderson MA, Hassan S, Bowman M, Miles MF et al. Tumor-derived p53 mutants induce NF-kappaB2 gene expression. Mol Cell Biol 2005; 25: $10097-10110$.

27. Iwanaga $Y$, Jeang $K T$. Expression of mitotic spindle checkpoint protein hsMAD1 correlates with cellular proliferation and is activated by a gain-of-function p53 mutant. Cancer Res 2002; 62: 2618-2624.

28. Fontemaggi G, Dell'Orso S, Trisciuoglio D, Shay T, Melucci E, Fazi F et al. The execution of the transcriptional axis mutant p53, E2F1 and ID4 promotes tumor neo-angiogenesis. Nat Struct Mol Biol 2009; 16: 1086-1093.

29. Weisz L, Damalas A, Liontos M, Karakaidos P, Fontemaggi G, Maor-Aloni R et al. Mutant p53 enhances nuclear factor kappaB activation by tumor necrosis factor alpha in cancer cells. Cancer Res 2007; 67: 2396-2401.

30. Xu D, Wang Q, Gruber A, Bjorkholm M, Chen Z, Zaid A et al. Downregulation of telomerase reverse transcriptase mRNA expression by wild type p53 in human tumor cells. Oncogene 2000; 19: 5123-5133.

31. Zalcenstein A, Stambolsky P, Weisz L, Muller M, Wallach D, Goncharov TM et al. Mutant p53 gain of function: repression of CD95(Fas/APO-1) gene expression by tumor-associated p53 mutants. Oncogene 2003; 22: 5667-5676.

32. Buganim $\mathrm{Y}$, Kalo E, Brosh R, Besserglick H, Nachmany I, Rais $\mathrm{Y}$ et al. Mutant p53 protects cells from 12-0-tetradecanoylphorbol-13-acetate-induced death by attenuating activating transcription factor 3 induction. Cancer Res 2006; 66: 10750-10759.

33. Yan W, Liu G, Scoumanne A, Chen X. Suppression of inhibitor of differentiation 2, a target of mutant p53, is required for gain-of-function mutations. Cancer Res 2008; 68: 6789-6796.

34. Muller BF, Paulsen D, Deppert W. Specific binding of MAR/SAR DNA-elements by mutant p53. Oncogene 1996; 12: 1941-1952.

35. Donzelli S, Fontemaggi G, Fazi F, Di Agostino S, Padula F, Biagioni F et al. MicroRNA-128-2 targets the transcriptional repressor E2F5 enhancing mutant p53 gain of function. Cell Death Differ 2011; 19: 1038-1048.

36. Donzelli S, Fontemaggi G, Fazi F, Di Agostino S, Padula F, Biagioni F et al. MicroRNA-128-2 targets the transcriptional repressor E2F5 enhancing mutant p53 gain of function. Cell Death Differ 2012; 19: 1038-1048.

37. Donzelli S, Strano S, Blandino G. microRNAs: short non-coding bullets of gain of function mutant p53 proteins. Oncoscience 2014; 1: 427-433. 
38. Masciarelli S, Fontemaggi G, Di Agostino S, Donzelli S, Carcarino E, Strano S et al. Gain-of-function mutant p53 downregulates miR-223 contributing to chemoresistance of cultured tumor cells. Oncogene 2014; 33: 1601-1608.

39. Li Y, Prives C. Are interactions with p63 and p73 involved in mutant p53 gain of oncogenic function? Oncogene 2007; 26: 2220-2225.

40. Di Agostino S, Strano S, Emiliozzi V, Zerbini V, Mottolese M, Sacchi A et al. Gain of function of mutant p53: the mutant p53/NF-Y protein complex reveals an aberrant transcriptional mechanism of cell cycle regulation. Cancer Cell 2006; 10: 191-202.

41. Coffill CR, Muller PA, Oh HK, Neo SP, Hogue KA, Cheok CF et al. Mutant p53 interactome identifies nardilysin as a p53R273H-specific binding partner that promotes invasion. EMBO Rep 2012; 13: 638-644.

42. Neilsen PM, Noll JE, Suetani RJ, Schulz RB, Al-Ejeh F, Evdokiou A et al. Mutant p53 uses p63 as a molecular chaperone to alter gene expression and induce a pro-invasive secretome. Oncotarget 2011; 2: 1203-1217.

43. Lim LY, Vidnovic N, Ellisen LW, Leong CO. Mutant p53 mediates survival of breast cancer cells. Br J Cancer 2009; 101: 1606-1612.

44. Puthalakath H, Villunger A, O'Reilly LA, Beaumont JG, Coultas L, Cheney RE et al. Bmf: a proapoptotic $\mathrm{BH} 3$-only protein regulated by interaction with the myosin $\mathrm{V}$ actin motor complex, activated by anoikis. Science 2001; 293: 1829-1832.

45. Kutuk O, Letai A. Displacement of Bim by Bmf and Puma rather than increase in Bim level mediates paclitaxel-induced apoptosis in breast cancer cells. Cell Death Differ 2010; 17: 1624-1635.

46. Hinds MG, Smits C, Fredericks-Short R, Risk JM, Bailey M, Huang DC et al. Bim, Bad and Bmf: intrinsically unstructured BH3-only proteins that undergo a localized conformational change upon binding to prosurvival Bcl-2 targets. Cell Death Differ 2007; 14: 128-136.

47. Schmelzle T, Mailleux AA, Overholtzer M, Carroll JS, Solimini NL, Lightcap ES et al. Functional role and oncogene-regulated expression of the $\mathrm{BH}$-only factor Bmf in mammary epithelial anoikis and morphogenesis. Proc Natl Acad Sci USA 2007; 104: 3787-3792.

48. Lamb J. The Connectivity Map: a new tool for biomedical research. Nat Rev Cancer 2007; 7 : $54-60$.

49. Lamb J, Crawford ED, Peck D, Modell JW, Blat IC, Wrobel MJ et al. The Connectivity Map: using gene-expression signatures to connect small molecules, genes, and disease. Science 2006; 313: 1929-1935.

50. Bunney TD, Katan M. Phosphoinositide signalling in cancer: beyond PI3K and PTEN. Nat Rev Cancer 2010; 10: 342-352.

51. Sabatini DM. mTOR and cancer: insights into a complex relationship. Nat Rev Cancer 2006; 6: $729-734$.

52. Adorno M, Cordenonsi M, Montagner M, Dupont S, Wong C, Hann B et al. A Mutant-p53/Smad complex opposes p63 to empower TGFbeta-induced metastasis. Cell 2009; 137: 87-98.

53. Muller PA, Caswell PT, Doyle B, Iwanicki MP, Tan EH, Karim S et al. Mutant p53 drives invasion by promoting integrin recycling. Cell 2009; 139: 1327-1341.

54. Sauer L, Gitenay D, Vo C, Baron VT. Mutant p53 initiates a feedback loop that involves Egr-1/EGF receptor/ERK in prostate cancer cells. Oncogene 29: 2628-2637.

55. Wang W, Cheng B, Miao L, Mei Y, Wu M. Mutant p53-R273H gains new function in sustained activation of EGFR signaling via suppressing miR-27a expression. Cell Death Dis 2013 4: e574.
56. Grugan KD, Vega ME, Wong GS, Diehl JA, Bass AJ, Wong KK et al. A common p53 mutation $(\mathrm{R} 175 \mathrm{H})$ activates $\mathrm{c}-$ Met receptor tyrosine kinase to enhance tumor cell invasion. Cancer Biol Ther 2013; 14: 853-859.

57. Muller PA, Trinidad AG, Timpson P, Morton JP, Zanivan S, van den Berghe PV et al. Mutant p53 enhances MET trafficking and signalling to drive cell scattering and invasion. Oncogene 2013; 32: 1252-1265

58. Xu H, Yu Y, Marciniak D, Rishi AK, Sarkar FH, Kucuk O et al. Epidermal growth factor receptor (EGFR)-related protein inhibits multiple members of the EGFR family in colon and breast cancer cells. Mol Cancer Ther 2005; 4: 435-442.

59. Gaiddon C, Lokshin M, Ahn J, Zhang T, Prives C. A subset of tumor-derived mutant forms of p53 down-regulate p63 and p73 through a direct interaction with the p53 core domain. Mol Cell Biol 2001; 21: 1874-1887.

60. Strano S, Fontemaggi G, Costanzo A, Rizzo MG, Monti O, Baccarini A et al. Physical interaction with human tumor-derived p53 mutants inhibits p63 activities. J Biol Chem 2002; 277: $18817-18826$

61. Girardini JE, Napoli M, Piazza S, Rustighi A, Marotta C, Radaelli E et al. A Pin1/mutant p53 axis promotes aggressiveness in breast cancer. Cancer Cell 2011; 20: 79-91.

62. Tan EH, Morton JP, Timpson P, Tucci P, Melino G, Flores ER et al. Functions of TAp63 and p53 in restraining the development of metastatic cancer. Oncogene 2014; 33: 3325-3333.

63. Leong CO, Vidnovic N, DeYoung MP, Sgroi D, Ellisen LW. The p63/p73 network mediates chemosensitivity to cisplatin in a biologically defined subset of primary breast cancers. J Clin Invest 2007; 117: 1370-1380.

64. Rocco JW, Leong CO, Kuperwasser N, DeYoung MP, Ellisen LW. p63 mediates survival in squamous cell carcinoma by suppression of p73-dependent apoptosis. Cancer Cell 2006; 9 : $45-56$.

65. Ibrahim N, He L, Leong CO, Xing D, Karlan BY, Swisher EM et al. BRCA1-associated epigenetic regulation of $\mathrm{p} 73$ mediates an effector pathway for chemosensitivity in ovarian carcinoma. Cancer Res 2010; 70: 7155-7165.

66. Wong SW, Tiong KH, Kong WY, Yue YC, Chua CH, Lim JY et al. Rapamycin synergizes cisplatin sensitivity in basal-like breast cancer cells through up-regulation of p73. Breast Cancer Res Treat 2010; 128: 301-313.

67. Subramanian A, Tamayo P, Mootha VK, Mukherjee S, Ebert BL, Gillette MA et al. Gene set enrichment analysis: a knowledge-based approach for interpreting genome-wide expression profiles. Proc Natl Acad Sci USA 2005; 102: 15545-15550.

(c) Cell Death and Disease is an open-access journal published by Nature Publishing Group. This work is licensed under a Creative Commons Attribution 4.0 International License. The images or other third party material in this article are included in the article's Creative Commons license, unless indicated otherwise in the credit line; if the material is not included under the Creative Commons license, users will need to obtain permission from the license holder to reproduce the material. To view a copy of this license, visit http://creativecommons.org/licenses/by/4.0/ 